\title{
Tea Tourism as a Marketing Tool: A Strategy to Develop the Image of Sri Lanka as an Attractive Tourism Destination
}

\author{
P. I. N. Fernando ${ }^{1}$, R. M. P. D. K. Rajapaksha ${ }^{1}$ and K. W. S. N. Kumari ${ }^{3}$ \\ ${ }^{1,2}$ Faculty of Management, Uva Wellassa University of Sri Lanka \\ ${ }^{3}$ Faculty of Science and Technology, Uva Wellassa University of Sri Lanka \\ imalif@uwu.ac.lk,poornidinitra@gmail.com, sandya_nilimi@yahoo.com
}

\begin{abstract}
Tourism is one of the world's largest industries as well a provider of employments over to 100 million populations around the world. Niche tourism refers to strategy that specific tourism product personalized to meet the needs of a particular tourist segment. Hence Tea tourism has been identified as one niche Tourism segment emerged with novel concept of sustainable and nature based eco-friendly tourism. Research objective is to identify the potentials to promote Sri Lanka as a tea tourism destination with special reference to Badulla and Nuwara Eliya districts by investigating the tea tourists' attitudes, expectations and destination attributes and local community involvement for tea tourism. Sample consists with 173 tea tourists and structured questionnaire and semi structured interviews were adopted in primary data collection. The numerous potentials have been identified which will be in capable of promoting tea tourism. Destination image building with the brand name of "Ceylon Tea", global promotional campaigns with the collaboration of Social Media Marketing tools as well introducing sustainable tourism experience packages has been recommended.
\end{abstract}

Keywords: Destination Image Building, Niche Tourism, Sri Lanka, Tea Tourism

\section{Introduction}

Travel \& Tourism is one of the world's largest economic sectors as providing direct employments over to 100 million as well enormous indirect employments for different sectors and regions (World Travel and Tourism Council). International tourist arrivals grew by $4.4 \%$ in 2015 to reach a total of 1,184 million in 2015 , according to the latest UNWTO World Tourism Barometer. With the gradual development of the tourism sector, people willing to engage in new tourism experiences and concepts as niche tourism emerged as a new concept (Fernando, 2014; Fernando 2015). Niche tourism refers to how a specific tourism product can 
be personalized to meet the needs of a particular tourist segment as Tea tourism has been identified as one niche Tourism segment emerged.

Tea could be stated as a beverage, a plant, an art, a meal service, an export, an agricultural product, an industry, a religion or a dedicated pastime (Yang, 2007) and tea is an integral part of food service (Jolliffe, 2007). Tea plant had its origins in China and later introduced to other countries and adopted as a beverage in different cultures and owning tea traditions. A peripheral industry built up around tea focuses on the production of goods for a tea-loving public, including tea accessories, books on tea, and a variety of tea-themed gift wares. Tea combination has developed as an art (Shalleck, 1972) and in some societies, such as Japan, as a religion. For many, the romance and history of tea and the experience of consuming tea is a pastime (Pratt, 1982) as includes collecting, either associated with the purchase of tea and related items such as teapots and teacups, or the seeking out and build-up of tea experiences, individually or as part of an organized tea tour.

Tourism noticeably has the potential to enhance the brand image and marketing of tea-producing destinations as contemporary tourists seek out authentic and unique experiences related to the appreciation and consumption of the beverage and tea encourages both consumption and the development of relationships. Climatic and geographic conditions have formed appropriate possibility for tea cultivation and historical evidences proved that tea tree has a long history dates back to the late 19th Century. Ceylon Tea and Tourism are inseparable words as Sri Lanka's tea growing areas are undoubtedly the most beautiful places in the island as well attractive tourism destinations (Ceylon Tea Land, 2013).

Potentials for the development of the segment is enormous with the strengths as the tourism industry needs to push to strengthen Tea tourism being practiced to day to reap the optimum results and benefits, particularly with regard to the focused marketing efforts aimed at the high spending visitors. End of thirty year civil war in Sri Lanka, there can be seen a remarkable development in tourism industry and a new paradigm has been introduced to focus more on Tourism income to the economy rather increase the tourists' arrivals (Fernando,2015). The nearly 150 year 
old tea industry was the main source of Sri Lankan economy for several decades (TRI, 2008) and Tea was the number one export product of Sri Lanka. Further the study will be important to industry, to identify potentials of Sri Lanka to become a tea tourism destination as limited literature available.

Based on the above arguments this study attempts to address following research questions.

- What are the potentials of Sri Lanka to become a tea tourism destination?

- What is the relationship between attitudes, expectation and destination attributes?

\section{Research Objectives}

The objectives of this study are:

- To identify potentials of Sri Lanka to become a tea tourism destination.

- To identify relationship between attitudes, expectation and destination attributes.

\section{Literature Review}

Tea being the most consumed beverage in the world after water, as the offering of a cup of tea is a universal sign of hospitality, in either a home or commercial hospitality setting (Walton, 2001). For hospitality, tea consequently serves as both a symbol and a resource with considerable potential for the provision of commercial hospitality. Home based traditions transfer over to the offering of tea in commercial hospitality settings. In china, they have great tea culture that creating a comfortable and positive experience for guests. Tea was brought into Europe in the early $17^{\text {th }}$ century, and the Dutch East India Company played a very important role (Han, 2007). In the $18^{\text {th }}$ century, tea became the most popular drink in England, and in the $19^{\text {th }}$ century, afternoon tea came into English routine life (Pettigrew, 2001; Han 2007 ) and late $17^{\text {th }}$ century, tea became mass product imported from china to Russia (Han, 2007).Tea has been a part of the history and economy of Sri Lanka since it was introduced in the late nineteenth century (Martin, 2007) and this was the main source of economy for several decades (TRI, 2008). Known as the 'Isle of Tea' 
(Heiss \& Heiss, 2007), the country has six major production regions as Kandy, Nuwara Eliya, Uva, Rathnapura, Dimbula, and Galle. Jolliffe (2003) studied on tea history, tea heritage and the tea industry in relation to tourism, mainly from the perspective of the relationship of tea to travel and of tea attraction supply. Tea destinations were identified as exhibiting characteristics of tea-related-history, traditions, ceremonies, cultivation, production, manufacturing, services, events and festivals. Further Tea tourism was defined as 'tourism that is motivated by an interest in the history, traditions and consumption of the beverage, tea' (Jolliffe, 2007).

Tea estates are part of the countries' diverse developed attractions. Sri Lanka has rich resources for supplying the tea related tourism experiences as nature walks in tea gardens, character accommodation informer tea factories and tea planter bungalows, tea tasting and retail in café's overlooking tea gardens and tours of producing factories. Scholars identified the tea industry must invest on value addition rather exporting in bulk (Athukorala, 2008) and it will pave way for new niches. Gunasekara and Momsen (2007) identified opportunities for the tea related tourism experiences in Sri Lanka. Destination choice of the tourists has been of great interest to tourism scholars (Pikkemaat 2004; Omerzel 2006; Nicolau and Mas 2004) and vital factors affecting destination choice process of a tourist has been examined. Generally, these factors are grouped into two categories called "push" and "pull" factors (Pikkemaat 2004) as push factors indicate psychological factors; values, motives and personality as well as social factors; age, education, marital status. Pull factors are destination related dimensions; these can contribute formation perceived attraction among tourists; distance, type of area, infrastructure, size of area, type of vegetation and activities in the destination (Lam and Hsu 2006: 590). Also, it is accepted that pull factors (attributes) could be grouped as intangible and tangible attributes (Pikkemaat 2004: 90; Lam and Hsu 2006: 591) From the point of destination attributes, Nicolau and Mas (2004) summarized 17 data sets and conducted to determine factors influencing destination choice of the tourist. 
Destination attribute identified as surface area, price, natural attributes, infrastructure, accessibility, reputation of the destination, programmed activities, entry prices, restrictions of navigation, population of species, time of journey, hotel size and services, parking areas and shops. On the other hand, Buhalis (2000 pointed 6A's framework including Attractions; natural, hand-made, artificial buildings, special events, Accessibility; transportation system, terminals and vehicles, Amenities; catering, accommodation, retailing and other tourist services, Available packages ;pre-arranged packages by intermediaries and principals, Activities; activities could be done by tourists while they are in the destination and Ancillary services; banking, telecommunications, posts and hospitals, etc. Identifying the significance of the Tea tourism as well community involvement as a whole this study focus on tea tourism from the demand by targeting the present tourists.

\section{Research Design and Methods}

Accordingly, the overall methodology of this study is structural questionnaires and follows survey method. The research questions provide an insight to understand and analyze the research problem. According to the nature of research questions, the study consists of both descriptive and inferential parts. The following figure shows the conceptual framework for this study.

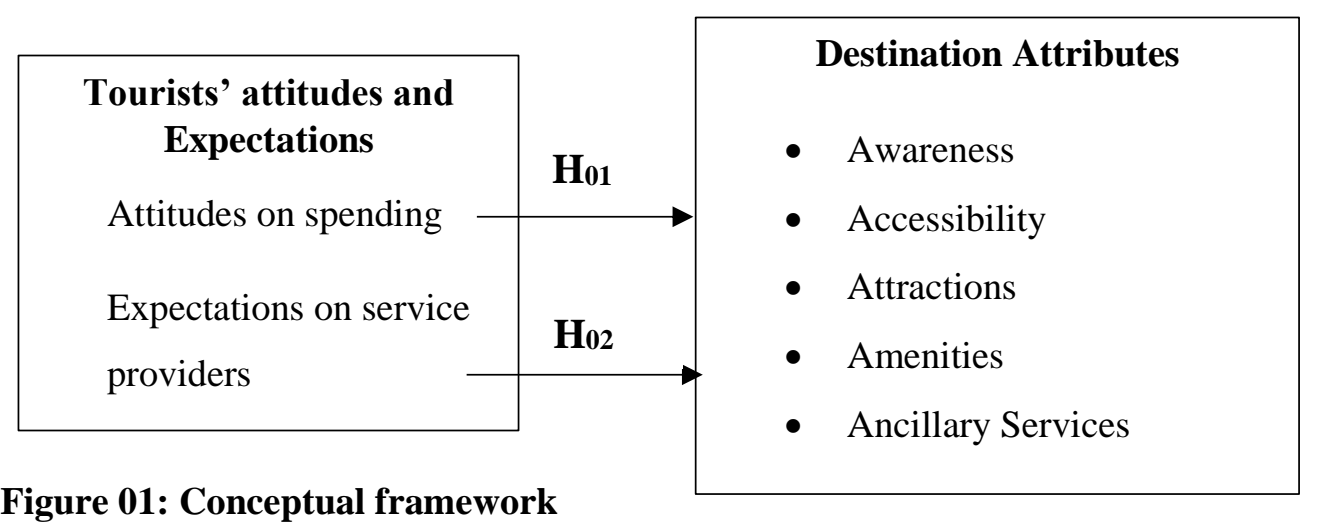

Source: Author Constructed 


\section{Hypotheses of the Study}

Following hypotheses are developed according to the conceptual framework.

- $\mathrm{H}_{01}$ : There is a relationship between Attitudes on spending of Tea tourists and Destination Attributes.

- $\mathrm{H}_{02}$ : There is a relationship between Expectations on service providers and Destination Attributes.

\section{Operationalization}

\section{Table 01: Destination Attributes}

\section{Dimensions \\ Indicators}

Awareness about Ceylon Tea

Awareness

Awareness about Tea Tourism destination in Sri Lanka

Awareness about Tea Tourism Activities in Sri Lanka

Accessibility

Availability of proper transportation system

Availability of vehicle parking facilities

Peaceful atmosphere

Attractions

Manmade attraction

Special events offered by destination

Leisure activities of destination

Ancillary Services

Availability of Telecommunication

Availability of safety and security

Availability of Sanitary facilities

Instructions and guidance

Availability of Health care

Availability of Bank services

Availability of food and beverage outlets

Amenities

Availability of Accommodation

Availability of retail shops 
Table 02: Tourists' attitudes and expectations towards tea tourism

\section{Dimensions Indicators}

Expected amount of spending for

- Accommodation

Attitudes on - Food and beverages

spending - Transportation

- Tours for Tea Tourism activities

- Other pleasure activities

Expectations on Service providers are capable of providing enough information

service Usage of international languages other than English

providers Service providers are capable of providing guidance

\section{Methodology}

Majority of tea plantations are located in Central and Uva Provinces let the choice of Nuwara Eliya and Badulla as the sample by conducting telephone interviews with current tea tourism practice locations. The study was strengthened through the triangulation of both quantitative and qualitative data which were obtained by means of the questionnaire survey and interviews. Primary data collected by questionnaires and interviews and secondary data collected from Sri Lankan Tourism Development Authority, websites, journal articles and books. Judgemental sampling method and Quantitative methods has been adopted. Sample consisted of 173 tourists travel to tea tourism practicing destinations on following locations (table 2) and researcher conducted a pilot survey for reliability and validity of the questionnaire. (The questionnaire of the study considered to be significant due to alpha value results more than 0.7, i.e. Cronbach's Alpha= 0.752)

Three factors; demographic factors, previous experience regarding tea tourism and their interest on tea are analysed through graphical representations to convey the potential tea tourists' profile. Regression analysis is used to analyse the relationship between expectations and attitudes of tourists and destination attributes of tea 
tourism destination, and multiple linear regression adopted with respect to study variables.

Table 03: Sample of the Study

\begin{tabular}{lcc}
\hline \multicolumn{1}{c}{ Destination } & $\begin{array}{c}\text { Average no of } \\
\text { Tourists Arrivals }\end{array}$ & Sample \\
\hline 1. Halpe Tea Factory -Ella & 25 & 7 \\
\hline 2. Dambetenne Tea Factory- Dambetenne & 10 & 3 \\
\hline 3. Heritance Tea Factory Hotel- Kandapola & 100 & 28 \\
\hline 4. Stafford Estate Bungalow - Ragala & 6 & 2 \\
\hline 5. Mandira Strathdon Bungalow - Hatton & 75 & 22 \\
\hline 6. Mandira Dickoya Bungalow-Dickoya & 75 & 22 \\
\hline 7. Craig Appin Bungalow-Dickoya & 75 & 22 \\
\hline 8. Mackwoods labookele Tea Centre-Labookele & 100 & 28 \\
\hline 9. Blue Field Tea Centre- Ramboda & 100 & 14 \\
\hline 10. Zesta Tea Cup- Hatton & 50 & 14 \\
\hline 11. Tea Trails- Dickoya & 50 & 2 \\
\hline 12. Tea Hills Bungalow- Hatton & 6 & 3 \\
\hline 13. Sherwood bungalow -Haputale & 10 & 2 \\
\hline 14. Kirchhayn Bungalow- Bandarawela & 6 & 2 \\
\hline 15. Thotalaga Tea Plantation bungalow- Haputale & 6 & 2 \\
\hline
\end{tabular}

\section{Results and Discussion}

Cronbach's Alpha reliability analysis determines the reliability of the questionnaire and the Alpha coefficient (0.862) indicates that the internal reliability and validity of questionnaire is satisfactory. There were 200 questionnaires distributed and collected from 173 Tea tourists who visit Tea tourism locations. When considering about distribution of region of origin majority were represented in Western Europe and their percentage were respectively 59\% (102), and United Kingdom, Germany, France, Denmark and Netherland were the main countries. Out of total respondents $12 \%$ tourists were Eastern Europeans and 17\% belongs to Eastern Asia. Highest 
percentage of Eastern Asian tourists belongs to China. Japan and Hong Kong represented rest of others. South Asian respondent's percentage is $6 \%$ and all of them were from India and Australian and New Zealand tourists represented 8\%.

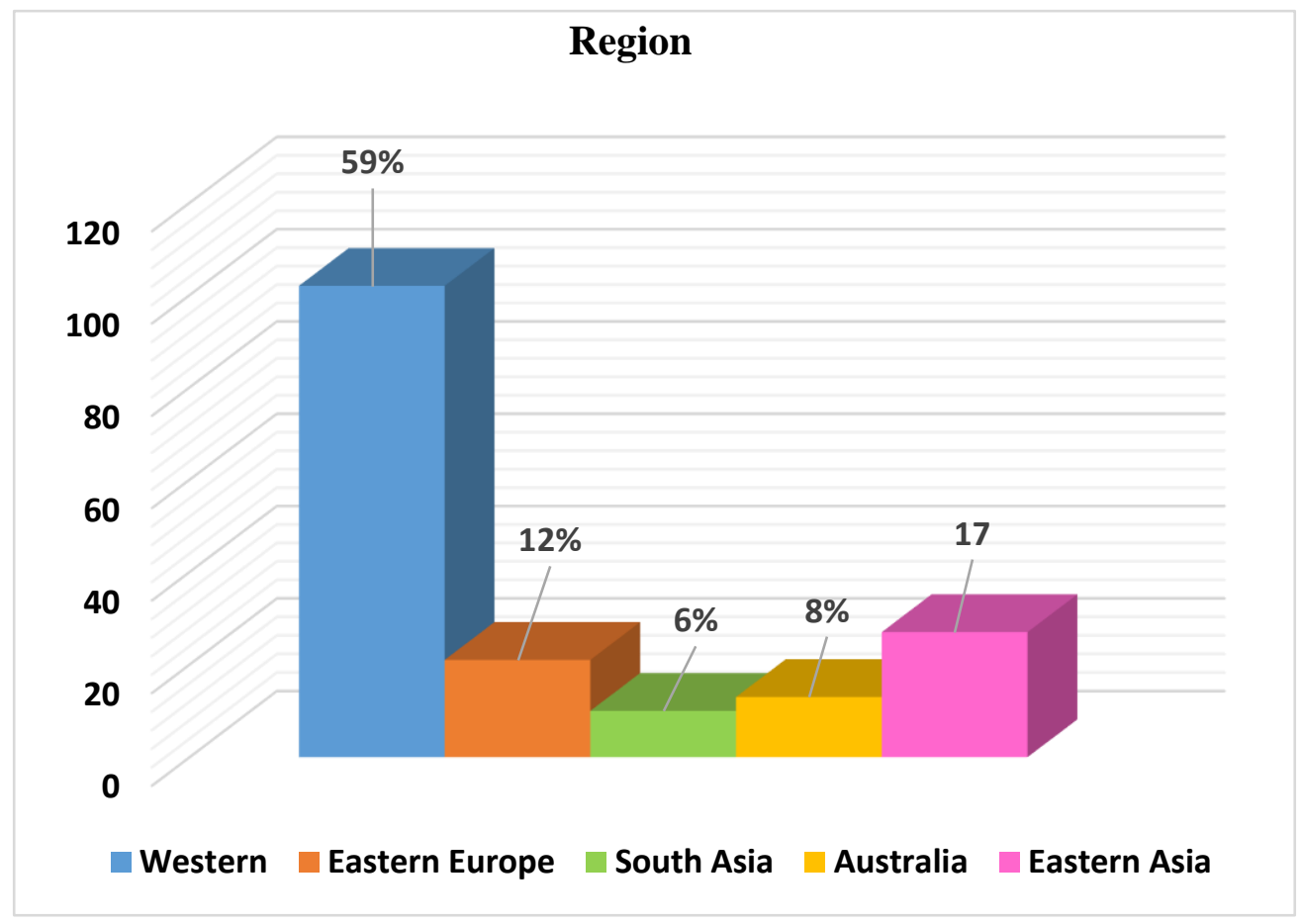

\section{Figure 02: Distribution of Region of Origin}

Source: Field Survey, 2016

Accordingly $73 \%$ respondents never visited, $23 \%$ had visited once or twice and $4 \%$ had visited Tea regions in world more than three times. Considerable amount of respondents most preferred tea tourism region is Sri Lanka and rest is for China, India and Indonesia and most preferred tea tourism areas are Nuwara Eliya and Halpe (Badulla). 
Table 04: Attitudes on Spending

\begin{tabular}{|lcccc}
\hline & Mean & Mode & Std. Dev & Variance \\
\hline Accommodation & 1.6 & 1 & 1.127 & 1.27 \\
\hline Food \& Beverage & 1.4 & 1 & 0.964 & 0.928 \\
\hline Transportation & 1.51 & 1 & 1.021 & 1.042 \\
\hline Tour for Tea Tourism activities & 1.21 & 1 & 0.676 & 0.456 \\
\hline Other pleasure activities & 1.47 & 1 & 0.931 & 0.867 \\
\hline
\end{tabular}

Source: Field Survey, 2016

According to the table 4, highest number of tourists attitudes on spending less than $\$ 200$ for accommodation and lowest number tourists spend between $\$ 401-500$ for accommodation. Further foods and beverages (F\&B) consists with 1.4 mean value and implies majority of tourists expected to spend less than $\$ 200$ for F\&B, transportation and Tea tourism activities.

Table 05: Expectations on Service Providers

\begin{tabular}{llllll}
\hline & Mean & Median & Mod & Std. Dev & Variance \\
\hline Expectations & 3.6492 & 3.6667 & 3.67 & 0.83558 & 0.698 \\
\hline
\end{tabular}

Expectations on service providers consists with 3.6492 mean value implies Tea tourists almost agreed that service providers are capable of providing enough information, capable in usage of international languages and capable of providing guidance. Coefficient of variation is $70 \%$ respectively illustrate tourists have different expectations towards skills of service providers.

Regression analysis is performed to study the linear relationships between attitudes on spending of tea tourists and destination attributes. 
Table 06: Model summary of simple linear regression analysis

\begin{tabular}{lc|}
\hline Figure & Value \\
\hline R Square & 0.298 \\
\hline Adjusted R Square & 0.273 \\
\hline Standard error of the estimate & 0.382 \\
\hline
\end{tabular}

Coefficient of determination $\left(\mathrm{R}^{2}\right)$ in Table 6 , suggested that $30 \%$ of total variation of destination attributes is described by attitudes on spending on tea tourists and $70 \%$ of unexplained variation is in this model. It appears that the model was fitted in fairly manner as explained variation is less than the unexplained variation. This implies that there are many variables can be related with destination attributes.

Table 7: Analysis of Variance for Simple Linear Regressions

\begin{tabular}{|lcccc|}
\hline Model & Sum of Squares & $\begin{array}{c}\text { Degrees of } \\
\text { Freedom }\end{array}$ & F & Sig. \\
\hline Regression & 5.735 & 1 & 28.356 & 0.017 \\
\hline Residual & 33.169 & 164 & & \\
\hline Total & 38.904 & 165 & & \\
\hline
\end{tabular}

Table 7 exposed that out of 38.904 of total sum of square, 5.735 of variation can be explained by regression. Further, it can be concluded that model is statistically significant at 0.05 level of significance ( $\mathrm{p}$-value $=0.017$ ). The fitted regression model can be summarized as follows.

\section{Destination Attributes $=3.665+0.075$ Attitudes on spending on tea tourists}

Further, the researcher was interested to investigate the relationship between Expectations on service providers and Destination Attributes as shown by Table 8 . 
Table 08: Model summary of simple linear regression analysis

$\begin{array}{ll}\text { Figure } & \text { Value } \\ \text { R Square } & 0.355 \\ \text { Adjusted R Square } & 0.350 \\ \text { Standard error of the estimate } & 0.349 \\ \text { Source: Field Survey 2016 } & \end{array}$

According to the results of table 8,35.5\% total variation of Destination Attributes is explained by expectations on service providers. The analysis of variance table and estimated coefficients for fitted regression model is summarized in Table 9.

Table 09: Summary of Fitted Regression model

\begin{tabular}{lcc}
\hline \multicolumn{1}{c}{ Model } & Coefficients & P- value \\
\hline Constant & 2.723 & 0.000 \\
\hline $\begin{array}{l}\text { Expectations on service } \\
\text { providers }\end{array}$ & 0.228 & 0.000 \\
\hline
\end{tabular}

\begin{tabular}{lcccr}
\hline Model & Sum of Squares & $\begin{array}{l}\text { Degrees of } \\
\text { Freedom }\end{array}$ & F & \multicolumn{1}{c}{ Sig. } \\
\hline Regression & 10.664 & 1 & 62.137 & 0.000 \\
\hline Residual & 28.317 & 165 & & \\
\hline Total & 38.981 & 166 & & \\
\hline
\end{tabular}

Source: Field Survey, 2016

Results of Table 9 is suggested that fitted regression model is significant at 0.05 level of significance $(\mathrm{p}$-value $=0.000$ ). The fitted regression model can be summarized as follows.

\section{Destination Attributes $=3.665+0.075$ Expectations on service providers}

Validity of the fitted model is checked at 0.05 level of significance and all error term assumptions are satisfied. Therefore, the fitted model can use for prediction. 


\section{Conclusions and Recommendations}

This study has taken the attempt to identify the potentials of Sri Lanka to become a tea tourism destination with special reference to Nuwara Eliya and Badulla districts. The profile of the tea tourists, Tourists attitudes, expectations and Destination Attributes has been taken into consideration in order to identify the potential. Majority of tea tourists were female, aged18-25 years /26- 35 years and more than half from Western Europe The highest percentage of tourists' annual gross income between US $\$ 40,000$ and $\$ 49,999$ and majority were influenced by online information and colloquialism. When considering tourists' experience profile, more than half of the respondents have never visited the tea tourism regions in the world. More than half of tea tourists desired to have day tour in tea tourism area and lack of activities in tea tourism outlets highlighted. The Attitudes on spending for accommodation, food and beverages, transportation, tea tourism activities and other pleasure activities, majority of tea tourists expected to spend less than US\$ 200. Tourists had good awareness about Ceylon tea tourism activities moderately. When considering about attractions, tea tourism destinations have peaceful atmosphere and more manmade attractions but less events and leisure activities. Presently one destination (Tea factory hotel, Kandapola) offer vast amount of tea tourism activities and others offer tea factory visit and tea tasting. Ancillary services; telecommunication, sanitary, healthcare and bank services should develop more than current situation. Regression analysis for Expenditure patterns of Tea Tourists and Destination Capabilities explained that relationship between expenditure pattern and destination capabilities are significant 0.05 level of significance.

Contribution to the local community from tourism is considerably less. Moderate number of people agreed that community people are benefiting from tea tourism. Tea tourism helps to improve the economic conditions of the local community who engaged as to improve household income of local people. Lack of capital, seasonality, government taxes and regulations and lack of infrastructure are the major problems faced by majority of community people who are engaged in tourism businesses. 
Therefore, following policy recommendations to the sector development as to achieve socio-economic development;

\section{Develop proper information base;}

- proper information base for tea tourism destinations, directions and activities/experiences for the tourists

International marketing plan to popularize tea tourism destinations and packages;

- Ceylon Tea brand name could be a marketing tool to attract European market

- Eco- friendly and sustainable tourism practices could be more marketable

- Social media marketing tools to attract more tourists

More leisure activities in tea tourism destinations;

- offer more tea tourism activities as plucking tea leaves, visiting tea plantation and knowledge sharing with tea plucking people, offering tea powder which is made by tea leaves plucked by tourists themselves and tea tasting

\section{Destination image building of Sri Lanka;}

- image building of Sri Lanka as a peaceful tourism destination where a tourists could enjoy a comprehensive leisure experiences

- nature based niche tourism sectors promote compared to traditional masstourism

- tourism experience packages offered to tourists rather catering traditional Sun and Sea tourism market

This research was funded by the Capital grants of Uva Wellassa University, Sri Lanka. 


\section{Reference}

Fernando I.N., (2015), What Competitive Strategies Way forward the Regional Competitiveness? A Comparative Economic Approach to Sri Lankan Tourism, International Journal of Business and Management; Vol. 10, No. $4 ; 2015$

Fernando I.N., "Tourism Competitiveness: A Cluster based approach for the Sri Lanka", International Conference on Contemporary Management (ICCM2014), University of Jaffna, 14-15 March, 2014

Goowalla, H. Neog. D. (2011) 'Problem and Prospect of Tea Tourism in Assam- A SWOT Analysis'. (2010) 'Tourists' Attitudes toward Tea Tourism'.

Jolliffe, L. (2006) 'Tea and hospitality: more than a cuppa', Contemporary Hospitality Management.

Jolliffe, L. (2007) Tea and Tourism: Tourists, Traditions and Transformations, Bristol, United Kingdom: Channel View Publications Ltd.

Jolliffe, L. (2003). The lure of tea: History, traditions and attractions. In C.M. Hall, L. Sharples, R. Mitchell, N. Macionis, \& M. Cambourne (Eds.), Food tourism around the world: Development, management and markets (pp. 121-136). Oxford: Butterworth Heinemann.

Jolliffe,L. Mohamed S.M. Aslam,M,S,M.(2009) 'Tea heritage tourism: evidence from Sri Lanka', Journal of Heritage Tourism.

Kim,K.H , Park,D.B (2014) 'Segmenting Green Tea Consumers by Purchase Motivation in South Korea ', Journal of Agricultural \& Food Information, Available at: http://dx.doi.org/10.1080/10496505.2013.774205

Leandra A Bedini, Dr Bonnie Canziani (2011) 'Exploration of Factors Associated with Tea Culture and Tea Tourism in United States, China and Taiwan'.

Pearce, M (2016) A Blend of Tea and Culture: Tours and Guides in Sri Lanka, Available at: http://theculturetrip.com/asia/sri-lanka/articles

Price water house coopers Sri Lanka () Sri Lanka Tea Board, Available at:http://www.pureceylontea.com/index.php/features/history-of-ceylontea (2016) go2HR, Available at: https://www.go2hr.ca

Simpson, M.C (2007) 'An integrated approach to assess the impacts of tourism on community development and sustainable livelihoods', Community Development Journal. 
Sproule, K.S (n.d.) 'Community-Based Ecotourism Development: Identifying Partners in the Process', Wildlife Preservation Trust International.

Sri Lanka Export Development Board (2016) Ceylon Tea based Tourism promises huge growth potential, Available at:_http://www.srilankabusiness.com.

Weerasingha, I. (n.d.) 'Role of Tea in Tourism Industry in Sri Lanka'.

Yang, L (2011) 'Tourists' perceptions of ethnic tourism in Lugu Lake, Yunnan, China', Journal of Heritage Tourism. 